\title{
Study on the Performance Testing and Optimizing the Use of Lithium Iron Phosphate Battery
}

\author{
Kang Song ${ }^{*}$, Peng Tian, Junbi Liao, Wencan Gao and Ruyi Gao \\ School of Manufacturing Science and Engineering, Sichuan University, Chengdu, China 610065 \\ ${ }^{*}$ Corresponding author
}

\begin{abstract}
Gathering real-time tracking for Charge-discharge voltage and temperature values of lithium iron phosphate battery.We can take full advantage of the charge-discharge characteristics of the battery to optimize battery usage, and ultimately improve the efficiency of the battery. The battery performance test system designed in this paper is based on STC12C5A60S2 microcontroller as the microprocessor, connecting the two pieces of AD7888 chip to achieve A/D acquisition and conversion, temperature measurement is connected to the temperature sensor through analog switches CD4051, collection of data via USB bus communications chips CH340T transferred to the host computer. The internal resistance of the battery can be calculated according to the difference between the former DC discharge and post-discharge voltage, obtaining the battery capacity by using the chargedischarge current and the time, the results show: the charge and discharge of the current and voltage difference caused by its internal resistance cannot be ignored and need to real-time correction; if need fast charging, select the constant current mode; when batteries are being stored for a long time, the battery voltage should be remained in the most stable discharge interval to ensure stable performance of the battery.
\end{abstract}

Keywords-lithium iron phosphate battery; the internal resistance of the battery; the battery performance testin

\section{INTRODUCTION}

Lithium iron phosphate has a high energy, good chargedischarge cycle, the stable output, big rate discharge, safety and the environment pollution-free characteristics, widely used in large electric vehicles, electric vehicles, solar complementary energy storage equipment and other fields [1].However, due to the positive and negative pole of each manufacturer and the quality and process of electrolyte material, there is a significant difference in the performance of the battery. And in actual use, in order to save time and make the best use of energy, it is likely not to charge and discharge in accordance with the standard or rated charging and discharging current, so it is necessary to test the performance of the battery and optimize the use of the battery by the test data.

Battery performance parameters are generally related to the internal resistance, capacity, charge and discharge voltage, temperature characteristics, life, self-discharge rate, etc [2]. In this paper, a battery performance test system is designed, which is used to control the charge and discharge voltage and current and temperature of the lithium iron phosphate battery in real time, and the performance of the battery can be judged by the analysis of the data. In this paper, a battery performance test system is designed, which is used to control the charge and discharge voltage and current and temperature of the lithium iron phosphate battery in real time, and the performance of the battery can be judged by the analysis of the data.

\section{Design of Performance Test System For LITHIUM IRON PHOSPHATE BATTERY}

\section{A. Principle Analysis}

1) Measurement of internal resistance voltage drop method

Any battery has its internal resistance, and the current measurement methods are the following: density method, open circuit voltage method, DC discharge method and AC method [3]. The voltage drop method used here is the DC discharge method.

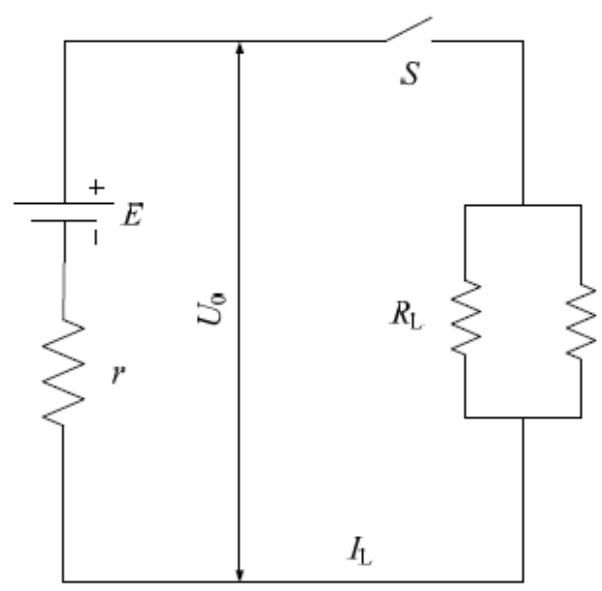

FIGURE I. INTERNAL RESISTANCE OF BATTERY EQUIVALENT CIRCUIT

As shown in Figure 1, when the switch $\mathrm{S}$ is switched off, the measured voltage $U_{0}=E$ battery potential, when the switch $\mathrm{S}$ is closed, the measured voltage due to the resistance partial pressure $U_{0}<$ E battery potential.

$$
\begin{gathered}
I_{\mathrm{L}}=\frac{U_{0}}{R_{\mathrm{L}}} \\
r=\frac{E-U_{0}}{I_{\mathrm{L}}}
\end{gathered}
$$




$$
r=\frac{\left(E-U_{0}\right)}{U_{0}} R_{\mathrm{L}}
$$

$R_{\mathrm{L}}$ measured by a low-resistance high-precision DC instrumentation, the accuracy can be to the $\mu \Omega$ level, and through the measurement of no-load battery voltage $\mathrm{E}$ between the two polesand load access between the two poles of the battery voltage $\mathrm{U}_{0}$, the internal resistance can be calculated.

\section{2) Capacity calculation}

The formula for calculating the capacity of the standard is the integral of current to the time, as shown below:

$$
C=\int_{t_{1}}^{t_{2}} I d t
$$

When the current is constant, it can be reduced to the product of current and time:

$$
C=I t
$$

Iis the current flowing through the load or charge into the battery, $t$ is the discharge time or charging time. At the time of charging and discharging, with the depth of the discharge or the battery power gradually, the actual current is always changing, so the simplified formula of definite integral is used in capacity calculation:

$$
C=\sum_{i=1}^{n} I_{\mathrm{i}} \Delta t
$$

The $\Delta \mathrm{t}$ in the formula is the collection of the battery voltage, in order to achieve high accuracy, usually set the sampling interval is a few seconds.

\section{B. Hardware Design}

\section{1) Multi-channel voltage acquisition}

In order to make the device better scalability,two 8-channel 12-bit AD7888 are used,the use of a reference voltage regulator chip provided voltage regulator chip $4.096 \mathrm{~V}$, therefore $\mathrm{AD}$ theoretical accuracy of the device can reach $0.001 \mathrm{~V}$.But in the actual measurement process, there may be interference caused by circuit voltage beating,perform error processing in the microcontroller,that is, each channel sampling 100 times, excluding the outliers, the maximum and minimum values, then averaged, so you can be precision control in less than 0.01V.Also AD device uses SPI data transmission, the use of single-chip SPI function, you can control the AD conversion and reduce the occupancy of I/O ports.

\section{2) Multi-channel temperature acquisition}

Temperature acquisition using the most commonly used DS18B20 temperature sensor,In order to get the battery positive and negative, discharge resistance, room temperature parameter, we used a total of eight temperature sensors and set aside four extensible interface.Due to the limited single chip microcomputer interface, the 8 channel analog switch chip
CD4501 is used as the controller of the temperature sensor,select the access temperature sensors in turn,and collect temperature values.All temperature sensors use a unified voltage power supply, so that the performance of the sensor is stable.

\section{3) Hardware protection and relay control circuit}

DC discharge current is large,the relay needs to be able to withstand large current conduction, so choose a car used 12V / 30A $\mathrm{BOSCH}$ relay.In addition, the high voltage may damage the battery and even causeaccidentsin the charging process, so we joined LM324 voltage comparator and logic gates 74LS02 constitute hardware protection circuitto prevent it.Finally ULN2803 drive the relay switching, as shown in Figure 2.

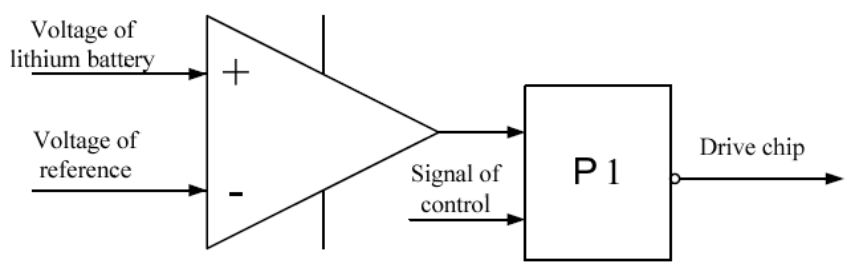

FIGURE II. DRIVE CIRCUIT WITH HARDWARE PROTECTION

\section{4) USB bus transfer}

Data is transmitted by ch340t chip, microcontroller serial port connecting one end, the other end data communication with the host computer via the USB port,no level conversion, communication is simple to use,good scalability and compatibility,but it is worth note that the chip should be electrified when the test system boot,to ensure synchronization with the computer terminal, as much as possible not to power down the middle, but when in contact with the serial port, you need a certain value resistor in series to prevent feedback current Impact.

\section{Program DESIGN AND DATA PROCESSING}

\section{A. Control Program Design}

The single chip microcomputer control program include buildinMultiple-functions, such as the two A/D 16 channel conversion test, 12 temperature sensor testing and serial port function test, andthe most critical is the battery performance automated test procedures that matches the PC software.

As shown in Figure 3, in order to make timely testing and control, all the procedures have been modularized, and nested loop between modules are interrelated. During program execution, if the corresponding flag is set,then enter the corresponding processing procedures, and no longer perform other complicated procedures,greatly reducing the executiontime of the program code.Regardless of the code, it is necessary to scan all the voltage and temperature values in advance and transfer to PC software to achieve real-time monitoring as well as the lower control program module to determine the conditions, and set theflag timely.

Static program is mainly used for when the battery charge or discharge is completed, disconnect the connection for battery selfrecovery,such as a battery is charged to full voltage, battery voltage will drop. And if discharge in the fully charged,the measured internal resistancevalue will have great error, soit must stand to wait for voltage down to the stable full power.No-load program is similar with static program,the main function is to send a sign to the host computer to make the upper computer start recording the voltage across the battery when the battery is empty. 


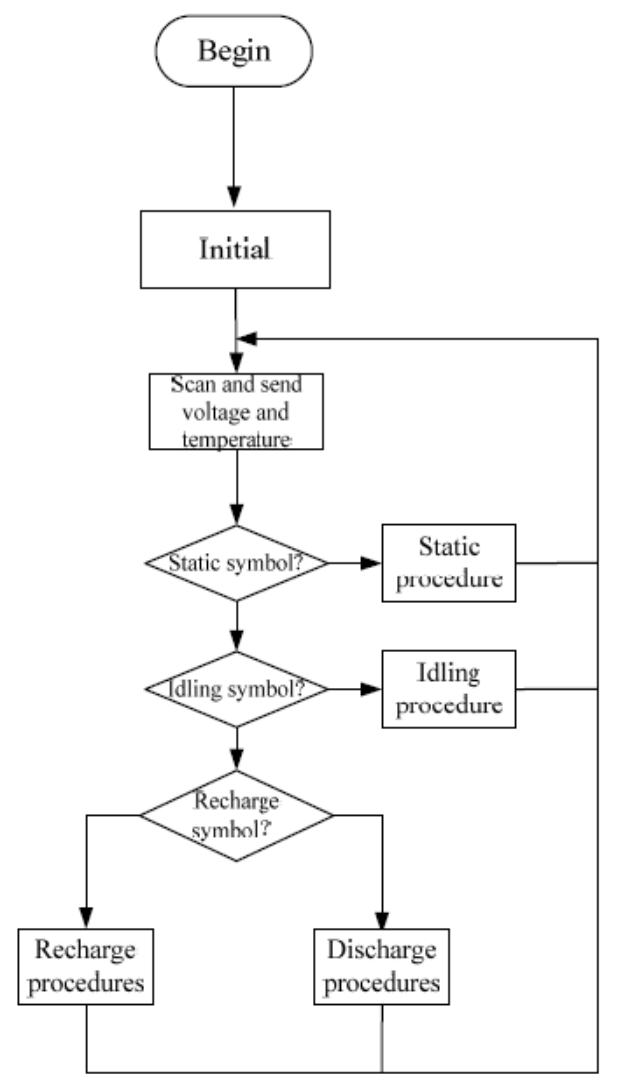

FIGURE III. TEST MAIN PROGRAM BLOCK DUAGRAM

\section{B. PC Data Receiving and Storage}

On the one hand, the software part of the upper computer monitors the battery in real time, on the other hand, processthe data according to the flag information send by lower machine.

All data are stored in the EXCEL table according to the given format, so it is easy for the processing of the data.In the process of data transmission, lower machine do the package transmission according to the fixed format.Host computer unpacked and isolated the relatedvoltagein accordance with therules of packing, and stored the temperature date in EXCEL。The first pageof Excel table is normal data for calibration of data comparison,the second page as the charge and discharge current for finishing the capacity and the relationship between capacity and voltage,page 3 for processing the data, including internal resistance.

\section{Data Processing}

Query the last time charge and discharge signs, the first data after the circuit interference will be volatile, and the time interval between the data is a few seconds, so we usethe average value of second and third data as a voltage drop data to ensure the reliability of data.Similarly, the similar method to obtain the current value, using the recorded value of no-load voltage, the voltage difference can be obtained to calculate the internal resistance of the battery.

Accumulating the current data,because the gap between the data is in seconds, the final sum needs to be converted into thestandard representation method of capacity A.H.

\section{DATA TeSt ANd Optimum USAGE}

\section{A. Test Platform}

Charge the battery by DC power, and the current and voltage is adjustable.DC power output $0 \sim 5 \mathrm{~V}, 0 \sim 100 \mathrm{~A}$.Discharge the battery by highpower resistance, four groups in all and each group have tow. High power resistance is $0.5 \Omega$, the power is $25 \mathrm{~W}$, and the test object is lithium iron phosphate battery, as shown in Figure 4.

\section{B. Test Data}

Table 1 shows the processed data, data is visual and easy to understand, you can clearly know the pressure drop, chargedischarge time and internal resistance of the battery and the charge-discharge capacity,which can do the most basic of cell performance evaluation through conventional analysis of data, you can get a more accurate performance parameters, Table 2 and Table 3 is the conventional data.

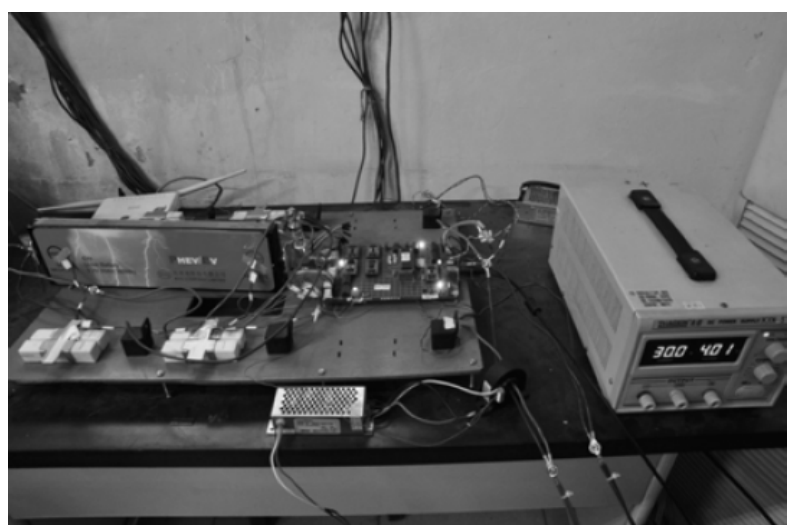

FIGURE IV. LITHIUM IRON PHOSPHATE TEST PLATFORM

TABLE I. DATA PROCESSING

\begin{tabular}{|c|c|c|c|c|c|c|c|c|}
\hline $\begin{array}{l}\text { ADfloating } \\
\text { voltage }(V)\end{array}$ & $\begin{array}{l}\text { ADcut-in } \\
\text { voltage(V) }\end{array}$ & $\begin{array}{l}\text { voltage } \\
\operatorname{drop}(V)\end{array}$ & $\begin{array}{l}\text { Discharge } \\
\text { time(s) }\end{array}$ & $\begin{array}{l}\text { Charge } \\
\text { time(s) }\end{array}$ & $\begin{array}{l}\text { Charge and discharge } \\
\text { capacity(A.S) }\end{array}$ & $\begin{array}{c}\text { Capacity } \\
\text { conversion(A.H) }\end{array}$ & $\begin{array}{c}\text { Charge } \\
\text { anddischar-ge } \\
\text { current(A) }\end{array}$ & $\begin{array}{c}\text { Internalresis } \\
\text { t-ance }(\boldsymbol{\Omega})\end{array}$ \\
\hline 3.298 & 3.203 & 0.095 & 821 & & 95801.41 & 26.612 & 40.035 & 0.002 \\
\hline 3.337 & 3.249 & 0.088 & 612 & & 73604.05 & 20.446 & 40.613 & 0.002 \\
\hline 3.337 & 3.409 & -0.071 & & 1287 & 38610 & 10.725 & 30 & 0.002 \\
\hline 2.983 & 3.034 & -0.051 & & 4974 & 149220 & 41.45 & 30 & 0.002 \\
\hline 3.284 & 3.178 & 0.106 & 512 & & 58461.79 & 16.239 & 39.722 & 0.003 \\
\hline 3.304 & 3.212 & 0.092 & 500 & & 59340.08 & 16.483 & 40.15 & 0.002 \\
\hline 3.419 & 3.336 & 0.083 & 483 & & 58089.79 & 16.136 & 41.176 & 0.002 \\
\hline
\end{tabular}


TABLE II. ROUTINE DATA

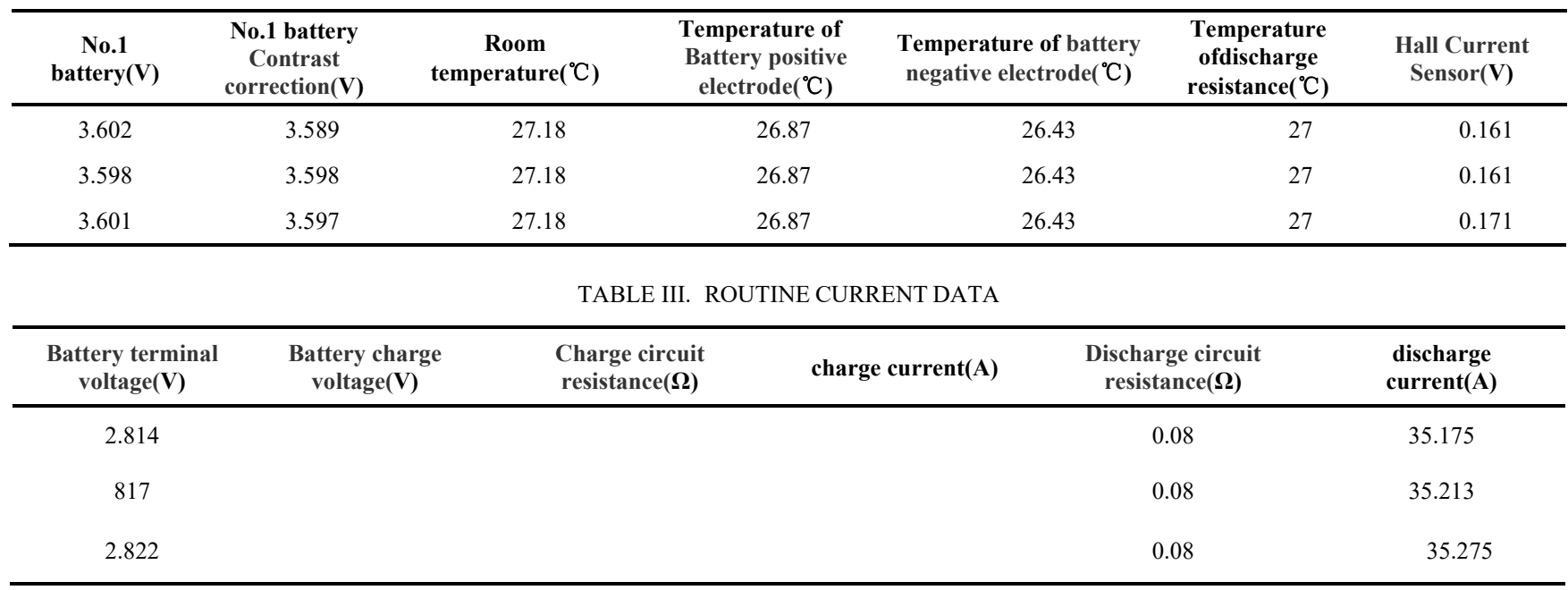

\section{Battery Performance}

The most intuitive way can we judge the battery is by the capacity resistance data, the bigger internal resistance battery is, the bigger instantaneous capacityis.In high-current applications, resistance consumption will be very significant [4].The data can be estimated battery capacity in case of use of different current charging and discharging time. You can choose the best suitable battery for the system required by the capacity of the internal resistance.

Then based on the battery voltage and current tracking data, analyze the relationship between the voltage and the capacity to obtain optimum battery charge and discharge section, you can know how to allocate resources to achieve optimal charge and discharge.

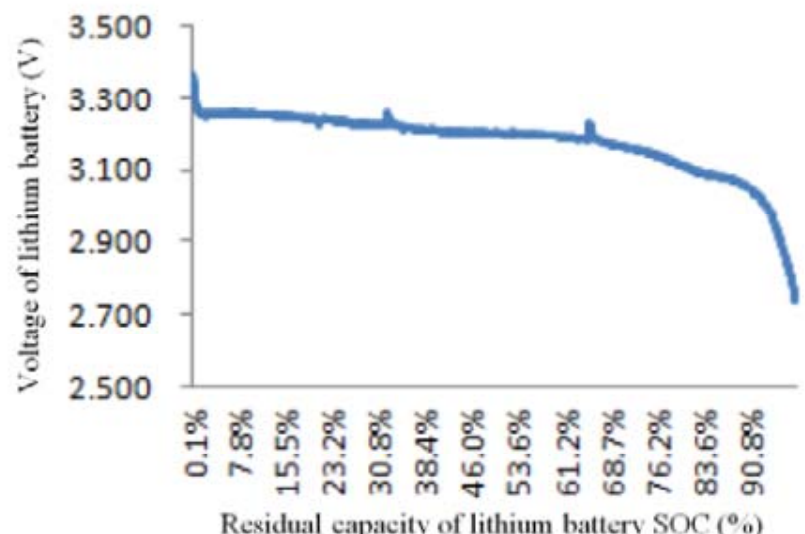

FIGURE V. BATTERY VOLTAGE AND SOC

Figure 5 shows the SOCvalue and voltage value of the battery across the battery being charged[5],As it can be seen the most stable storage segment is between $3.3 \mathrm{~V}$ to $3.4 \mathrm{~V}$, considering the influence of measured value of $\mathrm{A} / \mathrm{D}$ voltage on the high side caused resistance,so the actual value of the best energy storage segment should be lower than the measured value,where the charging current was $30 \mathrm{~A}$ and resistance for the $0.002 \Omega$, then the deviation value is $0.006 \mathrm{~V}$, the actual optimal storage can section is between $3.24 \mathrm{~V}$ and $3.34 \mathrm{~V}$.

There are two ways of charging of the test, constant current and constant voltage mode.When the battery is near full, the voltage rises rapidly from $3.5 \mathrm{~V}$ of course, trickle - charge can charge the battery in full [6]. But the Contrast data of trickle current and constant current can beused as a reference for the optimization of battery.

TABLE IV. TRICKLE AND CONSTANT CURRENT COMPARISON

\begin{tabular}{|c|c|c|c|c|}
\hline $\begin{array}{c}\text { Charging } \\
\text { mode }\end{array}$ & $\begin{array}{l}3.5 \mathrm{~V}- \\
3.6 \mathrm{~V}\end{array}$ & $\begin{array}{c}\text { time } \\
\text { consuming(s) }\end{array}$ & Capacity(A.H) & $\begin{array}{l}\text { Capacity } \\
\text { ratio(\%) }\end{array}$ \\
\hline $\begin{array}{l}\text { constant } \\
\text { current } \\
\text { constant } \\
\text { voltage }\end{array}$ & $\begin{array}{c}\text { constant } \\
\text { voltage } \\
3.65 \mathrm{~V}\end{array}$ & 1374 & 2.5 & $5 \%$ \\
\hline $\begin{array}{l}\text { constant } \\
\text { current }\end{array}$ & $\begin{array}{c}\text { constant } \\
\text { current } \\
30 \mathrm{~A}\end{array}$ & 180 & 1.5 & $3 \%$ \\
\hline
\end{tabular}

As can be seen from the table, the trickle charge can indeed be filled with more capacity, but also significantly increase the charging time.Compared to the constant current mode, trickle mode use more time with 20 minutes and more than $2 \%$ charge capacity.In actual use,especially under the timeliness of insufficient energy supply situation, as well as charging time is required,we must choose constant current charging, constant voltage constant current mode and vice versa.

We can see from Figure 6, the best discharge platform between $3.27 \mathrm{~V}$ to $3.27 \mathrm{~V}$, and then there will be a significant voltage drop. Like charging curve, here is the native data measured in the $\mathrm{AD}$ :the discharge current is $40 \mathrm{~A}$, the internal resistance is $0.002 \Omega$, and the actual voltage range is $3.35 \mathrm{~V}$ to $3.16 \mathrm{~V}$. There are two outstanding points in the picture, which is due to the discharge resistance temperature exceeds the set value,the test system has reached the awaited cooling stage, the cells began to recover, so the measured voltage will be slightly higher, the curve will show out in two points. 


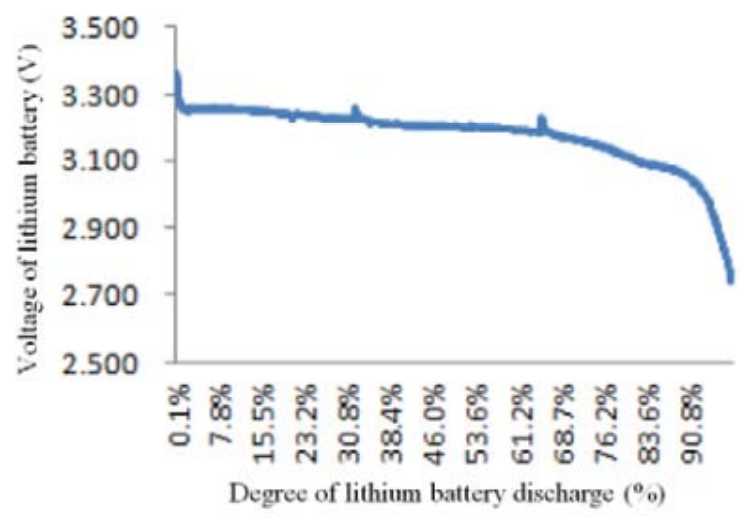

FIGURE VI. BATTERY VOLTAGE AND DEGREE OF DISCHARGE

TABLE V. ELECTRIC CORE VOLTAGE AND SOC

\begin{tabular}{cccc}
\hline $\begin{array}{c}\text { Electric core } \\
\text { voltage(V) }\end{array}$ & SOC(\%) & $\begin{array}{c}\text { Electric core } \\
\text { voltage(V) }\end{array}$ & SOC(\%) \\
\hline 3.158 & $10 \%$ & 3.303 & $60 \%$ \\
3.210 & $20 \%$ & 3.310 & $70 \%$ \\
3.255 & $30 \%$ & 3.325 & $80 \%$ \\
3.278 & $40 \%$ & 3.345 & $90 \%$ \\
3.291 & $50 \%$ & 3.386 & $100 \%$ \\
\hline
\end{tabular}

The capacity of the battery is about $60 \%$ of the nominal capacity, this is also the most stable interval. Compared to theprevious charging graph,the data of SOC span was $10 \%$, the most accurate energy storage is between $3.24 \mathrm{~V}$ to $3.24 \mathrm{~V}$.

Contrast charging curve and discharge curve, it can be seen that discharge less than filling the capacitythe internal resistance of $0.002 \Omega$ here, discharge circuit $0.08 \Omega$,the theoretical capacity of the release should be $97.56 \%$, but the actual release capacity of only $94 \%$, which means that there are other capacity loss.

Padhi[7]points out that only in very small current,canthe lithium iron phosphate battery reach the theoretical value.In the high rate charging and discharging, the transport rate of lithium ion in the lithium iron phosphate is lower than that of the reaction rate, which causes the degradation of the capacity. The smaller the size of the lithium ion is, the higher the rate performance of the lithium ion is.Because the test battery capacity loss is small here, so its performance is excellent.

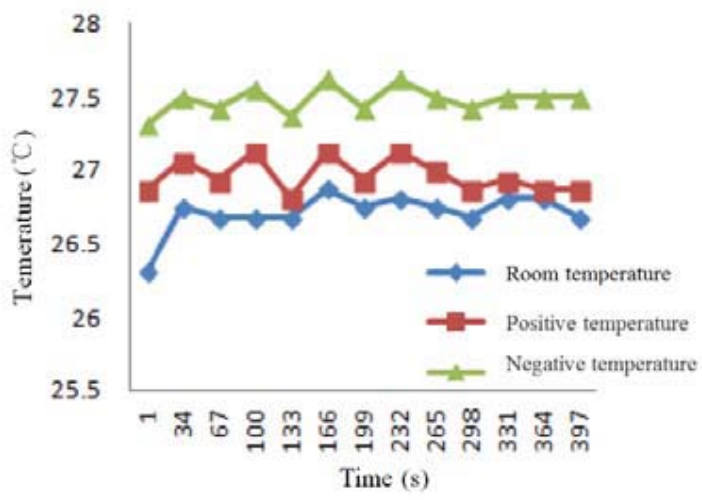

FIGURE VII. TEMPERATURE CHANGE CURVE CHART OF BATTERY CHARGING
As shown in Figure 7, in the process of chargingthe positive and negative temperature remained constant, while the negative temperature is higher than room temperature.

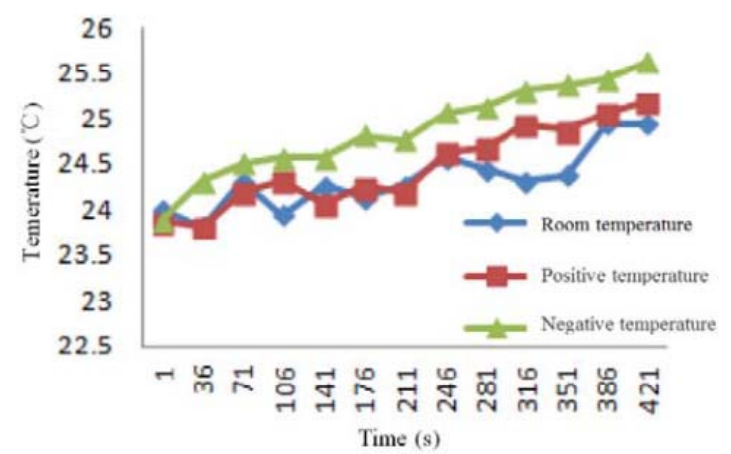

FIGURE VIII. TEMPERATURE CURVE OF BATTERY DISCHARGING

As can be seen from Figure 8,the temperature of positive negative plates,Positive and negative temperature is slightly higher than the room temperature, which also proves that the battery is still stable in the case of large current.

\section{Use Optimization}

First, we must choose the appropriate battery capacity, considering the relationship between the use of the battery and the current. On the premise of meet the system requirements, using different charge-discharge relationship.The residual capacity of SOC is corrected according to the parameters of the battery ${ }^{[8]}$. Shown in table 5, SOC with batteries voltage corresponding to obtain voltage value for the SOC value, and the batteries voltage with the following correction formula 7 .

$$
E=V \pm I_{(7)}
$$

Eis the cell voltage, $\mathrm{Vis}$ the voltage value measured across the AD. I is charging current, $r$ is internal resistance.At the time of discharging,the real cell voltage is the sum of voltage value of $A D$ and voltage drop caused by internal resistance.So the discharge platform will be different in the case of different discharge current, but the electric core voltage is uniform.

At the time of charging,Measured $\mathrm{AD}$ voltage value minus the step-up voltage caused by internal resistance is the real cell voltage Different charging current of full voltage value is different.Of course, if only for full charging, we can directly charge it to $3.6 \mathrm{~V}$. As shown in the table 4,actualthe voltage rise of the speed is very fast and the capacity is relatively small when the value of SOC over the full value of the corresponding cell voltage.

If you do not use the battery for a long time, taking into account factors such as the battery self-discharge, charge the battery to the most stable range, can not only prevent batteries fatigue, but also can make the stable performance of the battery.

\section{CONCLUSIONS}

This article design the battery performance testing system based on single chip microcomputer, Use voltage-difference method to obtain the internal resistance, and track the battery charging and discharging voltage of temperature change in realtime. We can evaluate the battery performance by analysis the test data. According to the performance based on different 
environments, we can further optimize battery usage and improve the utilization rate of the battery.

\section{ACKNOWLEDGMENT}

The authors would like to thank the sponsor of Cooperation Projects between Schools and Enterprises (2014CDLZG24),Science and Technology Support Program of Sichuan Province (2012GZ0094), National Natural Science Foundation of China (Grant No. 61271329) and National Natural Science Foundation of China (Grant No. 51405314).

\section{REFERENCES}

[1] ShuhongZHAO, FengWU, ZidongWANG. Study on operating mode cycle performance of lithium ion power battery with natural graphite and LiFePO4[J]. Electronic Components and Materials, 2009, 28 (11): 43-47.

[2] WeiZENG, Haibotang, WeiHAN, Laishuili, BinYE, DonglinGao. Performance testing system for electric vehicles powerbattery [J].Chinese Journal of Power Sources, 2001, 25(1): 35-39.

[3] LiweiLI, JiyanZou. Research on the internal resistance measuring device for battery[J]. Chinese Journal of Power Sources, 2003, 27(1): 42-44.

[4] ZhijieZHANG, MaodeLI. Effect of internal resistance on temperatre rising of lithium-ion battery [J]. Chinese Journal of Power Sources, 2010, 34(2): 128-130.

[5] WeSHI, JiuchunJIANG, SuoyuLI, RongdaJIA. Research on SOC estimation for LiFePO4 Li-ion batteries 「J].Journal of Electronic Measurement and Instrument, 2010, 24(8): 769-774.

[6] WenrongYANG, ZhizhouLI, LuluLI, RuohanLI. Battery Capacity Display System of Lithium Battery Pack Based on Virtual Instrument[J]. Electronic Measurement Technology, 2012,35 (10) : 91-94.

[7] GOODENOUGH J B, PADHI A K, NANJUNDA-SWAMY K S, et al. Cathode materials for second-ary(rechargeable) lithium batteries: U.S. Patent 8, 282,691[P]. 2012-10-9.

[8] ZhenpoWANG, FengchunSUN.Study on the Characteristics of Li-Ion Batteries [J]. Tr ansactions of Beijing Institute of Technolog y, 2005, 24(12): 1053-1057. 